\title{
Qualitative and quantitative determination of caffeine by comparing its amount in variety of black and green tea leaves marketed in Quetta city
}

\author{
Samiullah $^{1 *}$, Farida Behlil ${ }^{2}$, Farrukh Bashir ${ }^{2}$, Rukhsana Qasim² ${ }^{2}$ Musarat \\ Fazal $^{2}$, Komal Titus ${ }^{2}$, Muzaffar Khan ${ }^{2}$ \\ ${ }^{1}$ Department of Chemistry, University of Baluchistan, Sariab Road Quetta, Pakistan \\ ${ }^{2}$ Department of Chemistry, SardarBahadur Khan Women University, Brewery Road Quetta, Pakistan \\ *Corresponding author email: sami435889@yahoo.com \\ Citation \\ Samiullah, Farida Behlil, Farrukh Bashir, Rukhsana Qasim, Musarat Fazal, Komal Titus, Muzaffar Khan. Qualitative \\ and quantitative determination of caffeine by comparing its amount in variety of black and green tea leaves marketed \\ in Quetta city. Pure and Applied Biology. Vol. 4, Issue 1, 2015, pp 9-14
}

\begin{tabular}{lll}
\hline \hline Received: 02/12/2014 & Revised:07/01/2015 & Accepted: 13/01/2015 \\
\hline \hline
\end{tabular}

\section{Abstract}

Six varieties of tea produced by various industries, consumed mostly, were investigated for the quality and quantity of caffeine by Ultra Violet-Spectrophotometer (UV-S). The objective of study was to know that whether the caffeine in boozed tea of green and black leaves are low or high. Further they were correlated for their quantitative analysis. Extraction provided colorless needles of caffeine characterized by IR Spectroscopy. The obtained results of UV-S provided the samples named as A, B, C and a, b, c caffeine concentrations indicated the secure range set by food and drug administration (FDA) except for the black sample $\mathrm{C}$ which carried greater level of caffeine. Key words:Caffeine; tea leaves; UV-spectrophotometer

\section{Introduction}

The Camelliasinensis plant is the main source of varieties of tea. The leaves which come from this plant are further processed in green leaves via shrivel and passing of vapors. The black tea undergoes into cutting, tearing and curling (CTC), and at suitable temperature it's fermented. The leaves which are completely oxidized turns into black tea and the leaves which are oxidized in controlled conditions are converted into green tea [1]. Historically, tea leaves are overlooked not as spiritually but as beneficial in the area of malfunctions, maintenance and elimination of poisonous substances from body $[2,3]$. Tea is not only an age-old and a renowned beverage, but also contains proteins, polyphenols, chlorophyll, alkaloids, carbohydrates and organic compounds. The tea vary from white, oolong and herbs but foremost tea is descripted as black and greenish, which are basically analogous in composition, but most of natural constituents are present in green tea due to less implication of oxidation process [4]. Black and green tea is liked in most respect because of their pleasant, fresh flavor and appearance. It is taken as a balance beverage of diet and equips the body. Drinking of black tea is going beyond in Europe, while in Asia and 
China the primary choice is green tea. However, the natural substances are not invariably useful when consumption goes beyond an average standard [5]. Recent research has revealed lots of advantages with few side effects of tea [6]. Black and green tea furnish a valuable source as it aids to sustain no accumulation of cholesterol, comfort the problem of vomiting, makes activation of mental condition, helps in somehow to cure cancer [7].

Both types of tea are boozing in all segments and domains of all age groups. Hence, caffeine concentration in tea has indisputable crucial role in the homeostasis of a person. On the basis of body per $\mathrm{Kg}$ weight only 0.3 $\mathrm{mg}$ of caffeine is allowed [8]. In United States of America, caffeine absorption via different supplements is about $80-85$ percent. Caffeine as a drug in tea emanates from alkaloid and reveal defense towards pests [9]. Drinking of black tea extensively, influence the mind and physiological change in attitude. The over oxidation of leaves result in more caffeine formation, and high uptake induce addiction. Caffeine proves to be hazardous in pregnancy condition, in a day only $0.2 \mathrm{mg}$ is believed to be secure [10]. When high amount of tea is consumed, negative impacts as shrinkage of blood vessels, nervousness arouse, imbalance of urination and more importantly prompt the chances of heart failure [11]. Lots of surveys take notice of caffeine antioxidant peculiarity but recent literatures necessitate that quantity facts are focused in regard to fitness [12]. FTIR (Fourier Transmittance of Infra Red) is an effective and advance analytical technique used for element quality in a substance, and to ascertain the quantity, a specific and error free UV-spectrophotometer is reliable [13]. However, caffeine should be extracted by using suitable organic solvents, considering the protonation like acids [14].

\section{Materials and Methods Sampling}

Total six different green and black tea leave samples were purchased from local market of Quetta city. The samples collected contained four branded (two green and two black) and two open tea leaves (one green and one black). Samples of black tea leaves like open, tapal and lipton were named as sample A, sample $\mathrm{B}$ and sample $\mathrm{C}$ respectively while green leaves like open,tapal, and lipton were named as sample a, sample b and sample c respectively.

\section{Washing of glass ware}

The chromic acid solution was used for soaking of all the beakers, and flasks, deionioized water was used to clean them.

\section{Extraction}

Chloroform was used as a main solvent for extraction. To conduct the test 10 gram $(\mathrm{g})$ of tea, $100 \mathrm{~mL}$ of distilled water and $10 \mathrm{~g}$ of calcium carbonate $\left(\mathrm{CaCO}_{3}\right)$ were added in a $250 \mathrm{~mL}$ conical flask. The mixture was boiled at $100{ }^{\circ} \mathrm{C}$ with constant stirring for 20 minutes. Than this mixture was filtered and filtrate was poured into another clean $250 \mathrm{~mL}$ flask. With gradual shaking, $70 \mathrm{~mL}$ chloroform was added into the filtrate. Mixture was shaken for 4 to 5 minutes and then left to stand for further 5 minutes, the aqueous and organic layers appeared and separated. The lower layer of chloroform contained soluble caffeine which was collected in small beakers while the upper water layer was discarded. Further, small beakers were covered with petri dish and kept for heating on sand bath for 2 hours at $40{ }^{\circ} \mathrm{C}$. The chloroform was evaporated to obtain caffeine. 


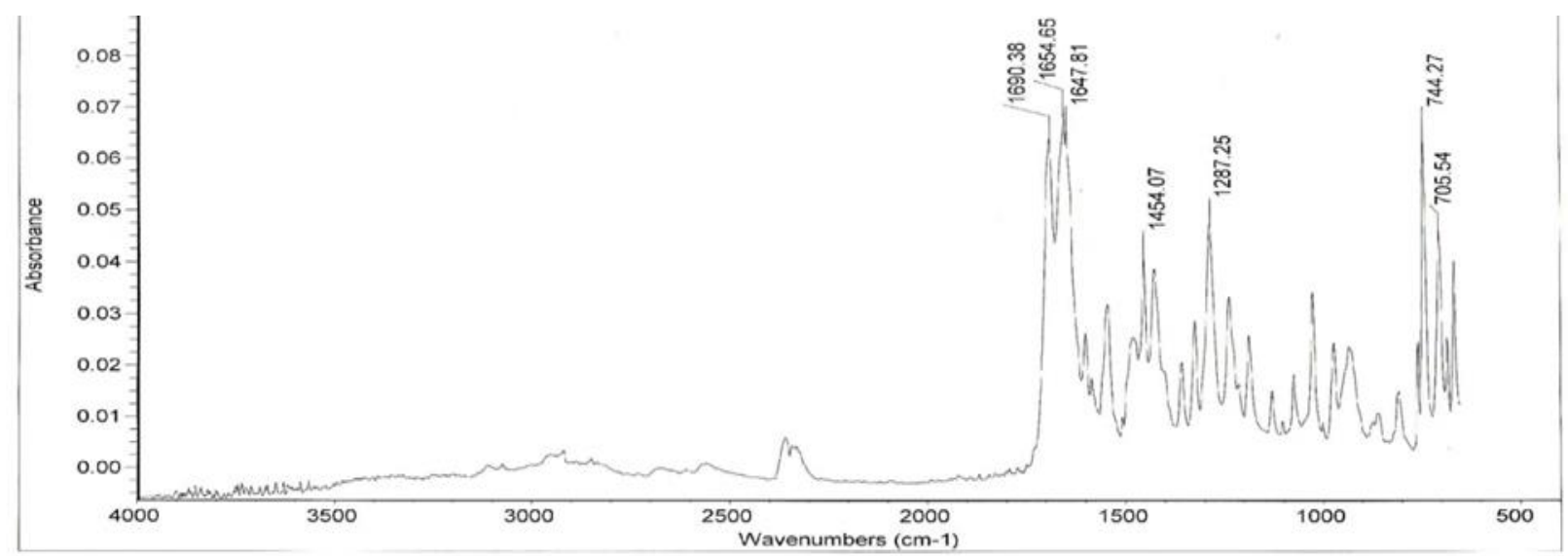

Fig.1. Absorbance of caffeine peak in standard solutions.

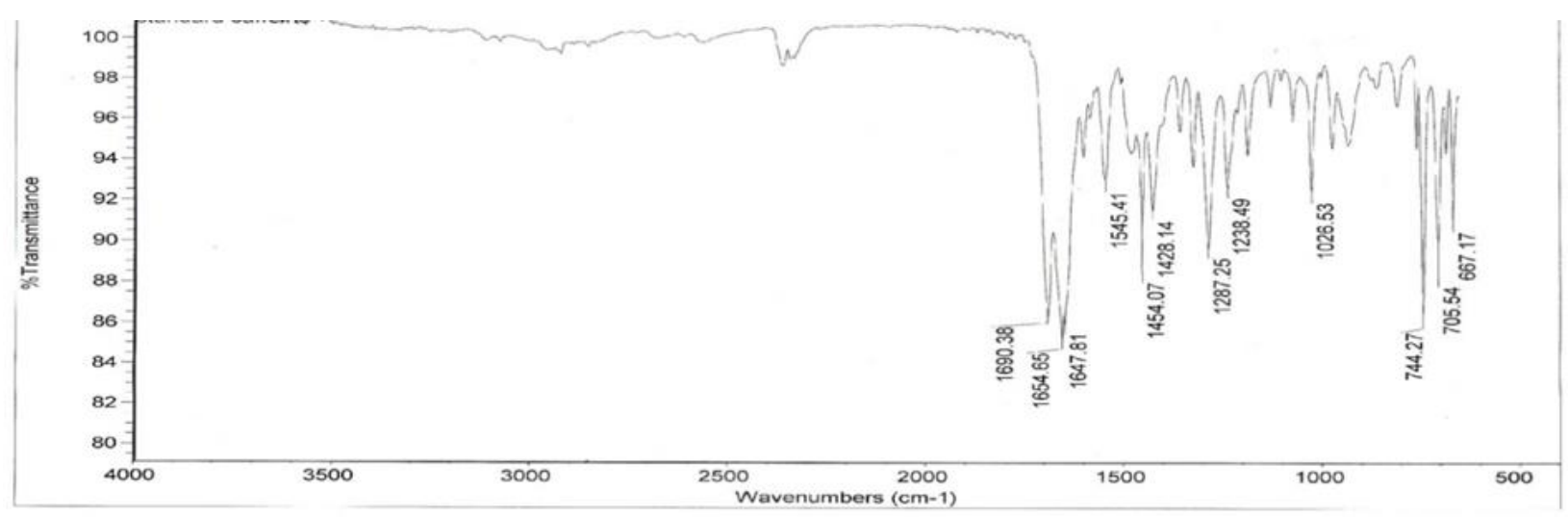

Fig.2. Caffeine transmittance in standard solutions.

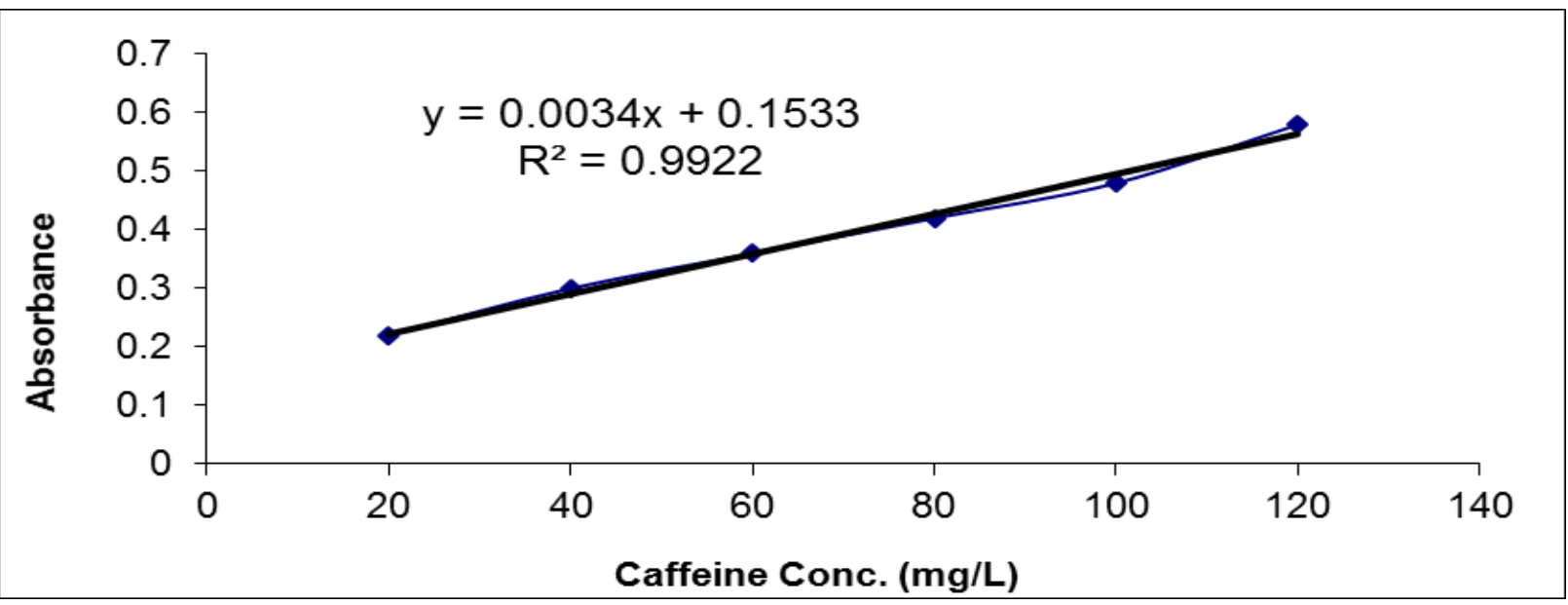

Fig.3. Calibration curve for standard caffeine concentration 


\section{Instrumentation}

Qualitative analysis of caffeine was carried by FTIR (Nicolet Avatar_330) and quantification of caffeine in all the samples were analyzed by UV-spectrophotometer (Shimaszu-1700).

\section{Qualitative Analysis}

The sample peaks were obtained by applied pressure in the compartment of FTIR, transmittance and absorbance of the sample were found out and the values were checked by FTIR chart in which functional groups values were given.

\section{Quantitative analysis}

Standard preparation

The stock solution of standard caffeine was prepared by taking $100 \mathrm{mg}(0.1 \mathrm{~g})$ caffeine into 100 milli-Litters $(\mathrm{mL})$ of distilled $\mathrm{H}_{2} \mathrm{O}$. From stock solution the working solution of different dilutions were prepared by taking 0 , 20,40,60,80, 100 and 120 ppm (parts per million or $\mathrm{mg} / \mathrm{L}$ ) in $25 \mathrm{~mL}$ of volumetric flask with the addition of $0.1 \mathrm{~mL}$ hydrogen chloride $(\mathrm{HCl})$ in each flask and filled the flask with distilled water up to the mark.

Sample preparation:

From the extracted caffeine of each sample $0.25 \mathrm{~g}$ of caffeine was taken in the $250 \mathrm{ml}$ flask containing $20 \mathrm{~mL}$ of distilled $\mathrm{H}_{2} \mathrm{O}$. Then 0.01 molar HClsolution was prepared and $10 \mathrm{ml}$ of this was added to the water and caffeine mixture in $250 \mathrm{ml}$ flask. Lead acetate $2 \mathrm{~mL}$ was added to the volume was made up to the mark. The solution was shaked for 1 minute and filtered. Sulphuric acid $\left(\mathrm{H}_{2} \mathrm{SO}_{4}\right)$ 4.5 molar solution was prepared and $0.2 \mathrm{~mL}$ of this was added into the $50 \mathrm{~mL}$ filtrate. Now flask was filled with distilled water. The sample flask solution and standard dilutions were analyzed at $274 \mathrm{~nm}$ through UVspectrophotometer. Same method was applied for all other samples.

\section{Results and Discussion}

Complete yield of caffeine from tea was obtained by using chloroform as extracting solvent. Chloroform being a polar organic solvent has high tendency of retaining caffeine, therefore most of the caffeine sample was obtained.

Table 1. Caffeine concentration in investigated samples of tea

\begin{tabular}{|c|c|c|}
\hline S.No. & Sample & $\begin{array}{c}\text { Concentration of } \\
\text { caffeine (ppm) }\end{array}$ \\
\hline 1 & Open black tea (A) & 114 \\
2 & Open green tea (a) & 112 \\
3 & Black tapal tea (B) & 110 \\
4 & Green tapal tea (b) & 28 \\
5 & Black lipton tea (C) & 118.5 \\
6 & Green lipton tea (c) & 114.5 \\
\hline
\end{tabular}

The brief presentation of standard caffeine gave transmittance and absorbance in the range of 1600. The extracted samples showed the transmittance and absorbance in the same region which confirmed the quality of caffeine in samples and comparatively near the highest peak. The absorbance and transmittance of standard and that of caffeinated tea are shown in fig. 1 and 2. Similar findings were reported by many researchers [1-3].

The absorbance of standard dilutions gave a linear curve at $274 \mathrm{~nm}$ as shown infig. 3; similarly the same wavelength was used for the caffeine extract absorbance range.The concentration of caffein in the test samples was determined by the calibration curve and comparison with the standard solution of caffeine. Calibration graph was obtained between the absorbance intensity on $\mathrm{y}$-axis and concentration of caffeine $(\mathrm{mg} / \mathrm{L})$ on $\mathrm{x}-$ axis. The calibration graph of absorbance intensity vs. caffeine concentration was linear over the range $0.22-.58 \mathrm{mg} / \mathrm{L}\left(\mathrm{r}^{2}=\right.$ $0.992 ; \mathrm{n}=6$ ) with regression equation $\mathrm{y}=$ $0.003 x+0.153[y=$ absorbance intensity, $x=$ concentration $\mathrm{mg} / \mathrm{L}]$ as shown in the figure 3 . The experiments have revealed that black tea contains higher concentrations of caffeine than green tea but within the standard 
limits.The results show that the samples A,B, and $C$ contain 114, 110 and 118.5 ppm, while samples a, b and c possessed the concentration 112, 28 and $114.5 \mathrm{ppm}$, which shows that the sample $\mathrm{C}$ and $\mathrm{c}$ of black and green tea contain higher amounts of caffeine respectively. Similar findings were reported by many researchers $[2,6-8]$.

The comparison of amount percentage of black and green tea leaves reveals that black tea contains higher concentrations of caffeine. The amount of caffeine in sample $\mathrm{C}$ is about 21 percent higher and other samples contain in the series of sample $\mathrm{c}>\mathrm{A}>\mathrm{B}>\mathrm{a}$ $>\mathrm{b}$ which are 20,19, 17, 17 and $6 \%$ respectively. Similar findings were reported by many researchers $[3,11-14]$.

\section{Conclusion}

The UV-spectroscopy technique was skillfully applied here for the evaluation of vital amount of caffeine in complex compounds of sample like tea which was procured from the shop of Quetta, Pakistan. The information gained directly from FTIR showed the inspected caffeine presence and the data was helpful to know the quantity of caffeine present in different kinds of tea brands. The result of our study is to assess and compare the caffeine quantity in black and green tea and to appraise that the black tea contains higher quantity of caffeine as compared to green tea.

On the basis of relative findings of this research it can be set forth for the future recommendation to investigate the factors which varies the caffeine limit in alike plants of unlike areas and further how quantitative reaction of caffeine differs from person to person, caffeine that matters with age and of working class of varying regions despite of the strong and weak tea. Also, work on contribution of those drinks containing caffeine that probably not put forward the normal cup of $50 \mathrm{mg}$, beside of the mentioned amount referred for physical practice of body. Moreover at national level the information should be given about the drug to aware the sport person, hence monitoring of its manufacturing, oxidation and packing must center.

\section{References}

1. Rabiul-Islam GM, Gias-uddin M, Mahfuz-ur-Rahman M\&Yousaf A (2013/). Caffeine and totalpolyphenols content of market tea cultivated and processed in Bangladesh. Mal. J. Nutr., 19(1):143147.

2. Luo M \& Peng H(2012). Study on determination of content of the main components of tea polyphenlos. Inter. J.of biosci.Biochem.and bioinform. 2(6):433-437.

3. Ali MM, Eisa M, Taha MI, Zakaria BA \&Elbashir AA (2012). Determination of caffeine in some Sudanese beverages by High PerformanceLiquid Chromatography. Pak J of Nutrition, 11(4), 336-342.

4. Atomssa T \&Gholap AV (2011). Characterization of caffeine and determination of caffeine in tea leaves using UV visible spectrometer. Afri.J. of pure and appl. Chem., 5:1-8.

5. Vuong VQ, Nguyen V,Golding BJ\& Roach PD (2011). The content of bioactive constituents as a qualityindex for Vietnamese tea. Inter. Food Res. J., 18: 329-336.

6. Sumary DP, Joesph WMP, Jomanga KE\&GomezuluE (2011) Indicative investigation of amount caffeine in some commercial teas and coffees foundin Dodoma Market. Tanz. J. of nat. and appl. Sci.,2(1):323-327.

7. Maughan JR\&Griffint J (2003). Caffeine ingestion and fluid balance. J.Hum.Nutr. Dietet.16: 411-420.

8. Zuo Y,Chen H\& Deng Y (2002). Simultaneous determination of catechins, caffeine and Gallic acid in green, oolong, black and pu-erh teas 
using HPLC with a photodiode array detector. Talanta, 57:307-316.

9. Hsiehs MB, Hsieh YP \&Bell LN (1996).Tea preparation and its influence on methylxanthineconcentration. Foodres.Inter., 29(3-4):325-330.

10. Erickson J (2011) Determination of the concentration of caffeine, theobromine and gallic acid in commercial teasamples. Concord. Coll. J. of Anal. Chem., 2:31-35.

11. Komes D, Horzic D, Belscak A, GanicKK \&Baljak A (2009). Determination of caffeine content in tea andmate tea by using different methods. Czech.J. Food Sci., 27: 213216.
12. Venkatesh S,Swamy MM, Reddy YSR, Suresh B \&Sethuraman M (1994). A simple method fordetermination of caffeine content in tea samples. Anci.Sci. of life, 14(12):35-38.

13. Verma R \& Kumar L (2010). Characterization of caffeine isolated from Camelliasinensis leaves of Sikkim Himalayan region. J. of chem. and pharm.Res., 2(4):194-198.

14. Purcarea C, Chis A, Vicas S, \& Fodor A (2008). Comparative studies about caffeine content in roasted ground coffee and in china black tea. Ecotoxicol. Zootech. SI technol. de indus. Alimen., 7:966-971 